\title{
Augmented Reality and tangible interfaces for learning
}

\author{
M. Carmen Juan Lizandra \\ Instituto Universitario de Automática e Informática Industria \\ Universidad Politécnica de Valencia \\ Camino de Vera, s/n. 46022 Valencia, Spain
}

\section{Introduction}

Recent advances in hardware, software, and methods are changing the way of learning for many students. These new methods include games and video games (Mayo, 2007) as well as Augmented Reality (Kaufmann, 2004). As just mentioned, Augmented Reality (AR) has already been applied for learning, entertainment, or edutainment. It has also been used in other fields such as: military; medicine; engineering design; robotic; telerobotic; manufacturing, maintenance and repair applications; consumer design; psychological treatments, etc. (Azuma, 1997; Azuma et al., 2001). In an AR system, users see an image composed of a real image and virtual elements that are superimposed over it. The most important aspect in AR is that the virtual elements add relevant and helpful information to the real scene. AR can be a successful tool in many fields since it can be applied anywhere where the information superimposed on the real world can help the user; learning is one of these fields.

In this chapter, we present a new AR game for learning about exotic animals that are not very well-known. The game uses tangible, magnet cubes as the user interface. Since the game uses AR, images as well as explanatory videos about the exotic animals can appear on the surfaces of the cubes. The main objective of this work was to develop an innovative AR system to allow people to learn about exotic animals in a fun way. The system is fun because it is played as a game. It is innovative because as far as we know there is no other AR system that has been developed for this purpose. Another objective was to evaluate different aspects of the AR game. Taking into account the multidimensionality of learning as well as $A R$ as a field, there are a number of aspects that can be considered in the evaluation. In our study, we have evaluated different aspects of the AR game such as: enjoyment and fun, perceived value, usability and sense of presence.

The rest of the chapter is organized as follow. Section 2 presents related works. Section 3 presents the AR game and includes the software and hardware requirements as well as a description of the AR game and the real game. Section 4 presents the results of the game evaluation. Finally, section 5 presents the conclusions, suggestions for improvements and future work. 


\section{Related work}

\subsection{Augmented Reality for learning}

This is not the first AR system that has been reported for learning, but AR systems have rarely been extensively evaluated. One of the few works that does include an evaluation is Kaufman's thesis (Kaufmann \& Schmalstieg, 2003; Kaufmann, 2004). He developed and evaluated Construct3D. It was designed to teach mathematics and geometry. Construct3D was tested with 14 students from two high schools in Vienna. All were 12th grade students. Half of the students were taught geometry using traditional paper and pencil construction methods ("The first group"). The other half ("The second group") used CAD programs regularly in classes to make most of the constructions. Both groups of students $(7$ students each) used Construct3D for 6 hours in total. The results from two evaluations showed that Construct3D was easy to use, required little time to learn, and encouraged learners to explore geometry.

A research group that has developed several AR systems for learning is the Mixed Reality Lab of Singapore (www.mixedrealitylab.org) (e.g. the Magic Story Cube, the sun system or how plants grow). The Magic Story Cube used a cube as a tangible interface that was folded or unfolded and, depending on the markers that were visible, the story was different. The Magic Story Cube presented the story of Noah's ark. In the sun system, several concepts that are related to the solar system were explained. In the plant system children learned how plants germinate, disperse, reproduce and perform photosynthesis.

Another research group that has also developed several AR systems in this field is the HIT Lab NZ (www.hitlabnz.org). The first one was The Magic Book (Billinghurst et al., 2001). It looked like a normal book, but there were markers on the pages, when the system recognized a marker, an image was shown or a story was started. A second work presented by this group was the AR Volcano. It was a system for learning about volcanoes, which included details on subduction, rifts, the Ring of Fire, volcano formation, eruptions and tectonic plates (Woods et al., 2004). A third work that is worthy of mention is the S.O.L.A.R system. It was an AR system for learning the position of each planet in the Solar System (Woods et al., 2004). Another work developed by this group is the BlackMagic. It was a MagicBook that told the history of the America's Cup (Woods et al., 2004).

Other groups have also been working on the development of different AR systems. For example, Shelton \& Hedley (Shelton \& Hedley, 2002) developed an AR system to teach the relation between the earth and the sun to geography students. Organic chemistry can also be taught using an AR system (Fjeld et al., 2007). Bimber et al. (Bimber et al., 2001) presented the Virtual Showcase. It placed virtual objects on real artefacts. One of the most outstanding applications was to place skin and bones on the skull of a Raptor dinosaur. Larsen et al. (Larsen et al., 2005) presented an AR system for learning how to play billiards. The most outstanding characteristic of this system was that the game was played on a real billiard table. The purpose of this system was to learn how to play billiards following sequences of exercises that were organized according to the user's level of ability. In 2006, Motokawa \& Saito (Motokawa \& Saito, 2006) presented an AR system for learning how to play the guitar. The system showed how to correctly hold the strings by overlaying a virtual hand model and lines onto a real guitar.

In 2007, two AR systems were included as activities in the Summer School of the Technical University of Valencia. The first AR system taught children the anatomical structures of the human body. Specifically, the children were able to 'open' the abdomen of a virtual human 
body using their own hands. They could see the areas where the stomach and the intestine were placed in the human body (Juan et al., 2008a). Forty children aged 8 to 10 years old took part in this activity. The children liked the system and were interested in using it for other educational purposes. The second system was an AR storytelling system for interactive stories where the children could choose how the story developed and the ending (Juan et al., 2008b). A story based on the Lion King was created in this system. The story had eight different endings. The story was shown on two different cubes, one that showed the story over all six faces of the cube and another where the story was only shown over one face of the cube. Forty-four children aged 6 to 8 years old took part in this activity. As in the above case, the children liked the system and were interested in using it for other educational purposes.

\subsection{Games and video games}

Games and video games have a great potential for learning. Several works have been reported for this purpose. McClean et al. (McClean et al., 2001) studied learning outcomes by comparing traditional lectures, web-based experiences and immersive games. They used a virtual-world-based geology game called Geography Explorer and a virtual-world-based biology game called Virtual Cell. The lectures produced the lowest learning outcomes. In comparison with the lecture method, the games increased learning outcomes by $15 \%-40 \%$ (Geography Explorer) and 30\%-63\% (Virtual Cell).

For teaching electrostatics, Squire et al. (Squire et al., 2004) used the Supercharged. They compared traditional teaching with teaching using the Supercharged game. They conducted a study with two different groups. In the first group, 32 students learned electrostatics through interactive lectures, teacher demonstrations, observations and experiments. In the second group, 58 students mostly played the Supercharged game during class time while also receiving lectures and handouts. The 32 students in the first group improved their understanding by $15 \%$ over their pre-test scores; those who played the game improved their understanding by $28 \%$.

A commercial developed algebra game, called Dimenxian (2005) was used in a study to evaluate the game's learning effectiveness (Mayo, 2007). In the study, the 75 students who played Dimenxian increased their algebra knowledge by one grade (i.e., from B to A). Underachieving students increased their test scores by as many as three grades by playing the game.

Virvou \& Katsionis (Virvou \& Katsionis, 2008) used the VR-ENGAGE game to teach students geography. They conducted a study of usability and likeability of VR-ENGAGE.

\section{Material \& methods}

To capture the video we used different Logitech cameras: QuickCam Pro 5000, QuickCam Pro 9000 and QuickCam Pro for Notebooks. We used the QuickCam Pro 9000 camera for the tests with the following features: Carl Zeiss lens; captured image size - 1600 x1200 at $30 \mathrm{fps}$; autofocus system and ultra-high resolution 2-megapixel sensor with RightLight 2

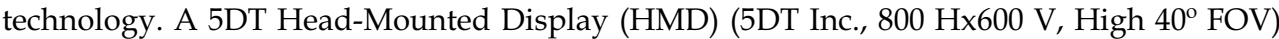
was used as the visualization hardware. Using a screen, the person in charge of the tests could see the same scene as the participant saw on the HMD. The camera was firmly 
attached to the HMD on the front part of the HMD. Figure 1.a shows the camera, and Figure 1.b

shows the camera attached to the HMD. To develop the system, we used the OsgART library developed by HITLab NZ (www.artoolworks.com/community/osgart). It is a C++ library that allows developers to build AR applications using the rendering capabilities of Open Scene Graph (OSG) and the tracking and registration algorithms of ARToolKit. OSG is a set of open source libraries that primarily provides scene management and graphics rendering optimization functionality to applications. It is written in portable ANSI C++ and uses the standard OpenGL low-level graphics API. ARToolKit is an open source vision tracking library that allows a wide range of AR applications to be easily developed (Kato \& Billinghurst, 1999). The required elements for the application are: a USB or FireWire camera, and a marker. A marker is a white square with a black border inside that contains symbols or letter/s.

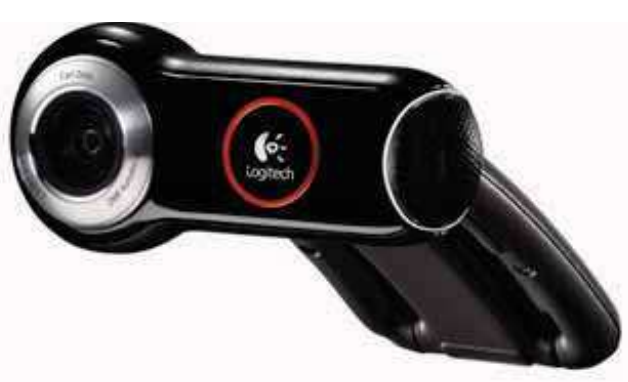

(a)

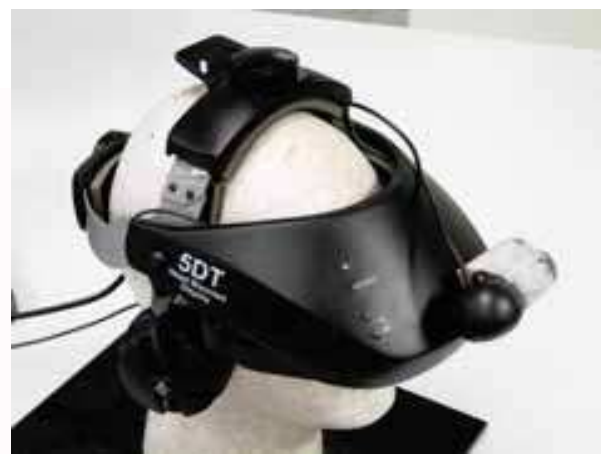

(b)

Fig. 1. a) QuickCam Pro 9000. b) Camera and HMD

In the AR game, the virtual elements that appeared over the markers were images and videos of exotic animals. The videos of the animals described the physical characteristics of the animal, its habitat and food. In order to be able to extend the game to other themes with minimum changes, we included as much information as possible in XML external files. We used three different kinds of XML files. The first XML file contained a collection of all the available questions, creating a kind of question database. This file contained a common part for each question which included the following: what the participant has to do when s/he has found the right animal; what to show when the animal is right or wrong; etc. All the questions were stored below the common part. The information required for each question was: the question identifier, the number corresponding to the correct image, the 8 images (possible answers) that appeared over the cubes with their identifiers and image paths, the video path, and the question to ask in order to find the animal. This file also included the textual content in different languages. Part of this file is shown in Figure 2. The second XML file contained the real set of questions to be used in the execution of the game. This file only stored the identifier of the questions that would be asked in the order established in the file. The third XML file was used to store the participants' scores. For the game, we had a total of 10 animals. These animals are: a guanaco, a calao, a cone, a corocoro, a lacewing, a mantis shrimp, a lycaon, a scaly anteater, a sawfish, and a ray. The cubes have a magnet in their interior. This magnet facilitates that two cubes can be held together in an easy way. 


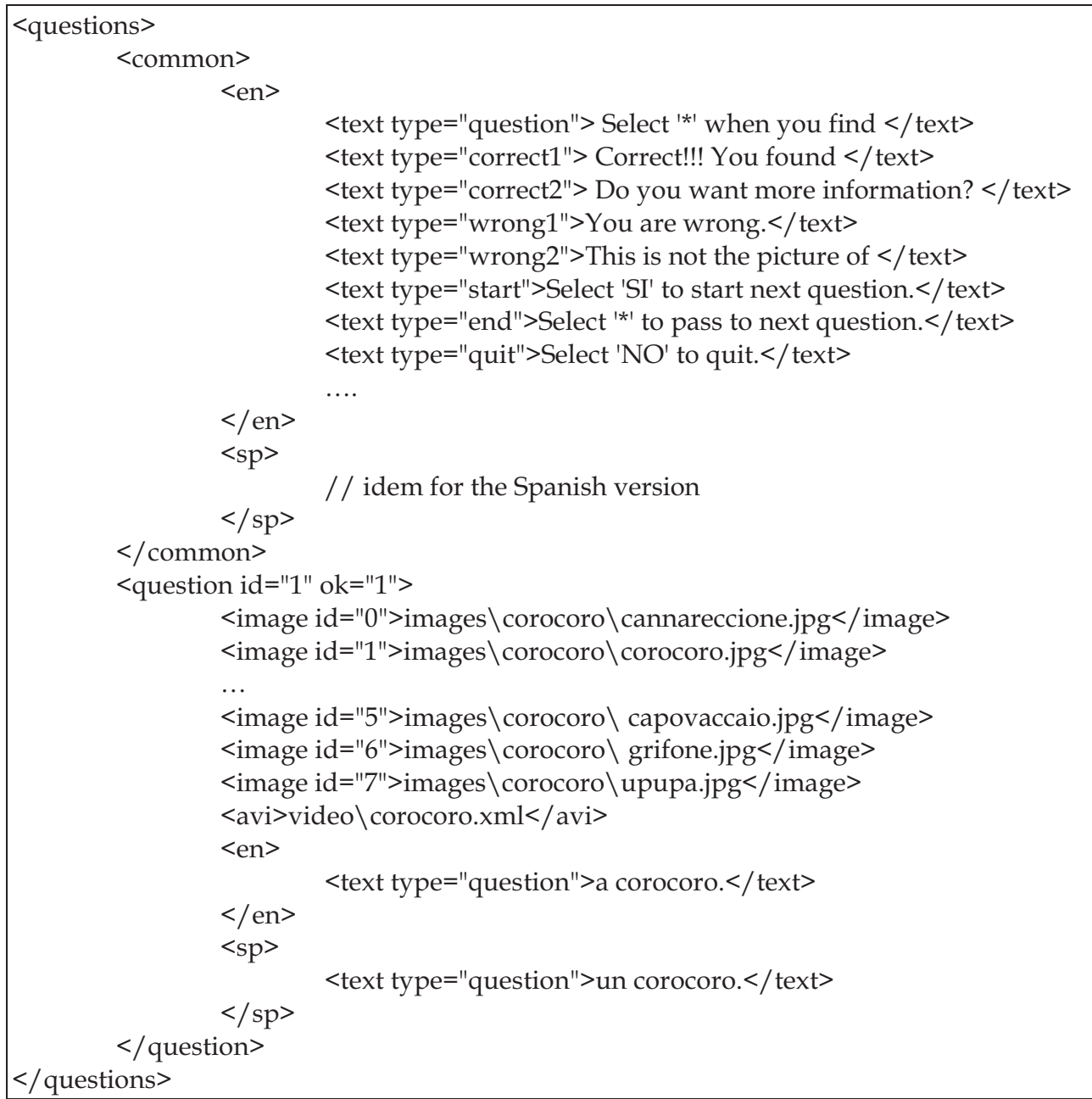

Fig. 2. Part of the first XML file

The basic steps in the AR game are:

1) Initialization of the video entry and download of the files that contain the pattern and camera data; the XML files containing information related to questions about the animals that are going to be asked about.

2) The game asks the participant to find the first animal by showing the question in the upper area of the screen. The participant turns both the center cube and the cube on the right. The center cube has two markers in two opposite sides (A and $\mathrm{B}$ ). The cube on the right has four markers in four continous sides (1, 2, 3 and 4). As a result of the combination of the markers of these two cubes, eight different combinations can be used. Therefore, eight different animals can appear over the two cubes. Figure 3 shows the three cubes used in the game. 
3) The system identifies the areas where the markers are located (center cube, A/B; right cube, $1 / 2 / 3 / 4)$. It recognises the visible markers and shows the related animal over them (e.g. Figure 4.a and Figure 5.a). If the participant thinks s/he has found the right animal, s/he has to select the side of the cube on the left that depicts the "*" symbol (e.g. Figure 5.b).

4) If the participant does not find the right animal, the game shows a message indicating this situation and the participant has to try again. If the participant finds the right animal, the game asks if $\mathrm{s} /$ he wants to know more about the animal. The participant has to select the side of the cube on the left that depicts "SI" for Yes and "No" for No. If the answer is no, the game goes to next step, 4 . If the answer is yes, the game shows a video over the front sides of the center cube and the cube on the right (e.g. Figure 6.a). It explains the characteristics of the animal, its habitat and food. The participant can skip the rest of the video by using the cube with the "*" symbol at any point.

5) The game asks if the participant wants to search for another animal. The answer is selected using the cube on the left as in previous step. If the answer is yes, the game repeats step 2; if the answer is no, the game ends.

6) At the end of the game, the participant receives a score that depends on the number of animals successfully found and the amount of time. The greater the number of found animals and the lower the time, the higher the score. The participants' score is then compared with the ten best scores that are stored in the XML file.

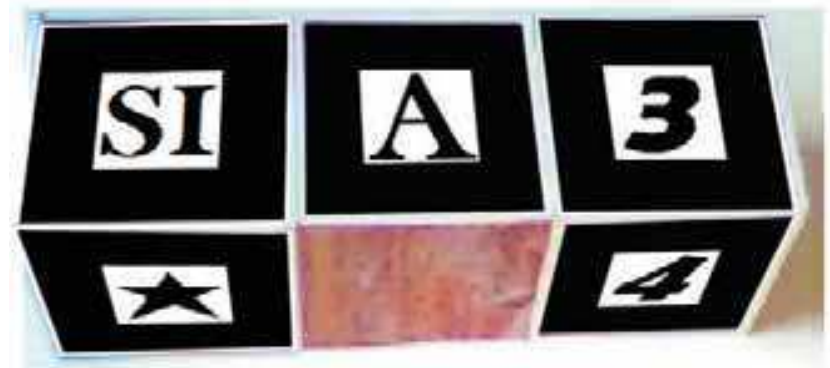

Fig. 3. The three real cubes used in the game

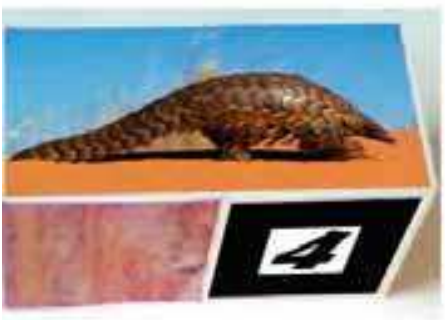

(a)

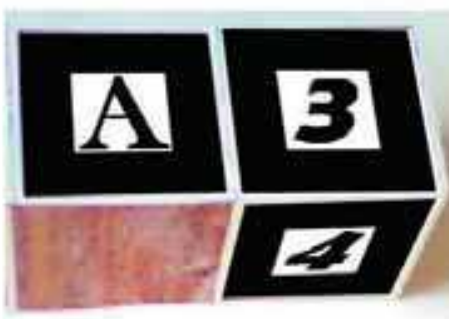

(b)

Fig. 4. a) AR game. A scaly anteater appears on the cubes as an augmented image.

b) The same cube as in Figure 4.a., but without an image 


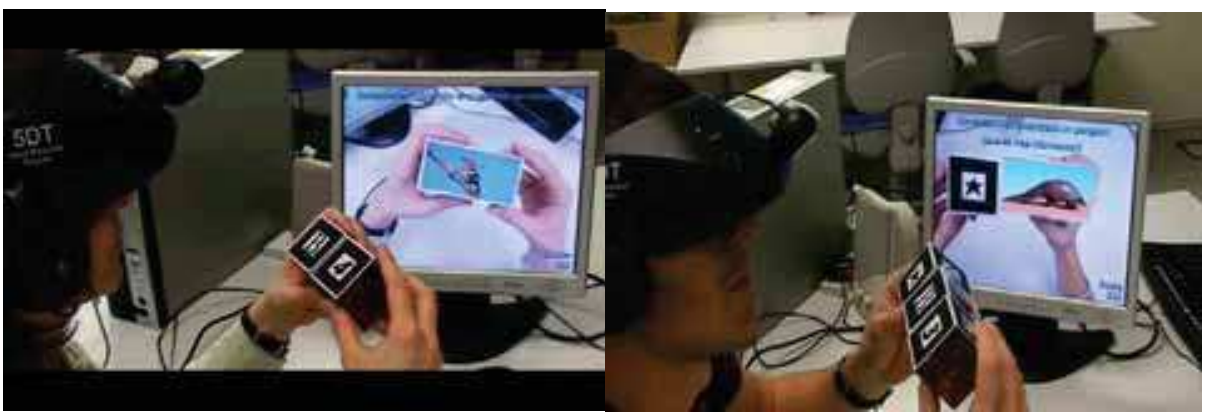

(a)

(b)

Fig. 5. a). A woman is trying to find a corocoro. b) A man has found a scaly anteater

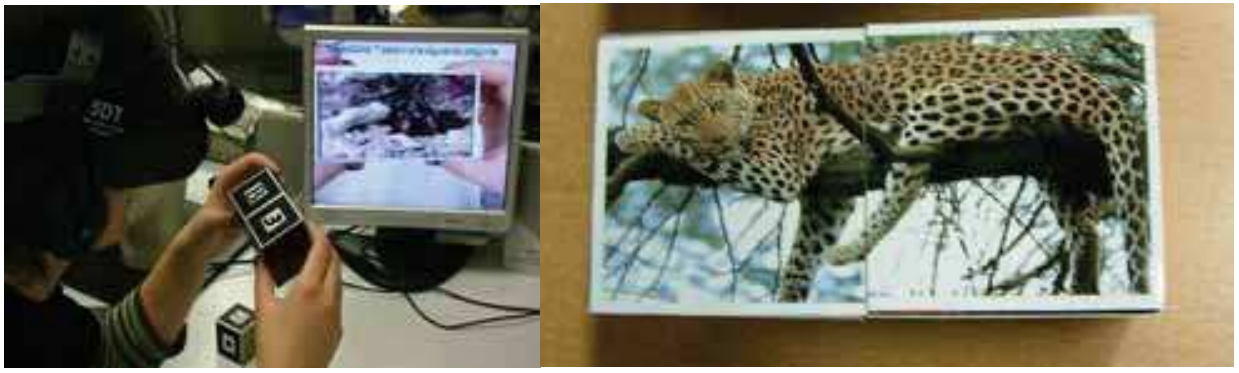

(a)

(b)

Fig. 6. a). A woman is watching the video about the mantis shrimp. b) Cubes of the real game

In order to validate the AR game, it has been compared with a real game. The basic steps in the real game are:

1) The person in charge of the validation asks the participant to find the first animal (using his/her voice). The participant uses two cubes to find the right animal. The images of four different animals appear as a combination of the faces of the two cubes. The images are real pictures that have been sticked over the cubes. Figure $6 . \mathrm{b}$ shows two cubes of the real game.

2) The participant turns the two cubes to find the right image. If the participant thinks $\mathrm{s} /$ he has found the right animal, $\mathrm{s} /$ he has to select the side of the cube on the left that depicts the "*" symbol (as in the AR game). The person in charge of the validation tells if $s /$ he is right or not.

3) If the participant does not find the right animal, the person in charge of the validation tells the participant to try again. If the participant finds the right animal, the person in charge of the validation asks if $\mathrm{s} /$ he wants to know more about the animal. The participant has to use the left cube to interact with the game (as in the AR game). If the answer is no, the game goes to next step, 4 . If the answer is yes, the person in charge of the validation shows a page with images and text. The text is the same that the video reproduces. It explains the characteristics of the animal, its habitat and food. The participant can go to the next step by using the cube with the "*" symbol at any point.

4) The person in charge of the validation asks if the participant wants to search for another animal. If the answer is yes, the game repeats step 1; if the answer is no, the game ends. 


\section{Results}

The study included 20 adult participants, 12 males and 8 females (aged from 16 to 44 years old, mean=24.1, SD=5.70). Thirteen participants were Computer Science professionals. None of them was expert in AR. Five participants were employees at the Technical University of Valencia. Another participant was a physical therapist. The youngest participant was a high school student. The study was carried out at the Technical University of Valencia. The participants did not receive any compensation for their time.

Participants were counterbalanced and assigned to one of two conditions:

a) Participants who used the real game first and then the AR game.

b) Participants who used the AR game first and then the real game.

The protocol was the following. Before using either game, the participants were shown an explanatory video about how to play the games. The participants then played the first game. After the game, the participants were asked to fill out a post-game questionnaire and an adapted version of the presence questionnaire by Slater et al. (Slater et al., 1994). After filling out the two questionnaires the participant played the second game. After playing, the participants were again asked to fill out the post-game questionnaire and the same presence questionnaire. Finally, they were asked to fill out a final questionnaire. The participants played with the AR game at about 15 minutes and with the real game at about 10 minutes. The post-game questionnaire had to be answered on a scale from 1 (not at all) to 5 (very much). The post-game questionnaire contained the following questions and statements. The questions are grouped by the aspect to evaluate.

Enjoyment and fun

AG1. Does the game seem fun to you?

AG2. Did you like seeing the questions/images/videos over your hands and the fact that you could move them?

Perceived value

AG3. Would you like to use this game for other subjects, e.g., plants, monuments of the world, etc.?

AG4. Do you think your friends would enjoy playing this game?

AG5. Would you like to play again another day?

Usability

AG6. Has it been easy to play?

AG7. Did you like using the cube for communicating with the game?

AG8. Was it easy to perform selections using the cube?

The presence questionnaire contained the following questions. The scoring was on a scale of 1-7.

P1. Describe on a scale of 1 (none)-7 (total) the level of sensation of reality that you had when the images and videos (in the AR system) appeared on the cubes?

P2. Were there moments during the game when you thought that the images on the cubes were real pictures?

P3. When you think back to your experience, do you remember the game more as a film you saw or more as a game you played?

P4. Think about your memory of "playing with cubes on which images and videos appeared". How similar is this memory to your memories of playing with other similar games?

P5. During the experience, did you often think that you were actually playing with cubes on which images and videos appeared? 
The final questionnaire contained the following questions:

A2P1. Which game did you like the most?

A2P2. Did you feel comfortable wearing the HMD?. The scoring was on a scale of 1-5.

A2P3. What did you like the most?

A2P4. What did you like the least?

This work evaluated different aspects of the AR game: enjoyment and fun, perceived value, usability and sense of presence. To do this, we compared subjective measures taken in a real game and in the AR game. Table 1 shows Student $t$ tests for the scores given to the postgame questionnaire after playing both games. The last row indicates whether there was a statistical difference between the two games for the related question. As this table shows, there was a statistical difference for questions 1-5, 7. For enjoyment and fun (AG1, AG2), the results indicate that participants perceived the AR game as being more fun than the real game (AG1). They liked the AR game more than they liked the real game since they could see the questions/images/videos over their hands and they could move them (AG2). For the perceived value (AG3), the results indicate that participants preferred the AR game for its use for other purposes. They also thought that their friends would enjoy playing the AR game more than playing the real game (AG4). In addition, they would prefer to play with the AR game again (AG5). For usability, we have included AG6-AG8. There were no statistical differences between the two games for AG6 and AG8, indicating that the perceived level of easiness was similar for the two games. There was a statistical difference between the two games for AG7, indicating that participants liked to play using the cube for communication with the AR game more than they liked to play using the real game.

In order to determine whether or not the order of play had an effect on the scores in the second game, the sample was divided into two groups (participants who used the real game first and participant who used the AR game first) and Student $t$ tests for the scores given to all questions were applied. No significant statistical differences were found using the AR game (see Table 2). This indicates that the order of play did not influence the participants' scores for the post-game questionnaire. With regard to the real game, no significant statistical differences were found for questions 1-4, 6-8 (see Table 3). This indicates that the order of play did not influence the participants' scores for the post-game questionnaire. The only question that presents a significant statistical difference was AG5. This indicates that the participants liked the real game for playing again if it was played first.

\begin{tabular}{|c|c|c|c|c|c|c|c|c|}
\hline Questions & AG1 & AG2 & AG3 & AG4 & AG5 & AG6 & AG7 & AG8 \\
\hline AR & $4.05 \pm$ & $4.75 \pm$ & $4.05 \pm$ & $3.7 \pm$ & $3.6 \pm$ & $4.15 \pm$ & $4.35 \pm$ & $4.05 \pm$ \\
& 0.76 & 0.44 & 0.83 & 1.03 & 0.75 & 0.99 & 0.81 & 0.89 \\
\hline Real & $2.4 \pm$ & $2.95 \pm$ & $2.75 \pm$ & $2.2 \pm$ & $2.35 \pm$ & $4.2 \pm$ & $3.1 \pm$ & $4.00 \pm$ \\
& 0.82 & 1.05 & 1.07 & 1.11 & 0.99 & 1.15 & 1.17 & 1.03 \\
\hline Stat. t & 8.43 & 8.01 & 5.38 & 6.10 & 6.14 & -0.18 & 4.63 & 0.18 \\
\hline Critical t & 2.09 & 2.09 & 2.09 & 2.09 & 2.09 & 2.09 & 2.09 & 2.09 \\
\hline Statistical & Yes & Yes & Yes & Yes & Yes & No & Yes & No \\
difference & & & & & & & & \\
\hline
\end{tabular}

Table 1. Student $t$ test for scores given to the post-game questionnaire after using both games, $\alpha=0.05$ 


\begin{tabular}{|c|c|c|c|c|c|c|c|c|}
\hline Questions & AG1 & AG2 & AG3 & AG4 & AG5 & AG6 & AG7 & AG8 \\
\hline AR First & $3.90 \pm$ & $4.70 \pm$ & $4.10 \pm$ & $3.40 \pm$ & $3.70 \pm$ & $4.20 \pm$ & $4.40 \pm$ & $4.10 \pm$ \\
& 0.88 & 0.48 & 0.74 & 1.27 & 0.68 & 1.03 & 0.70 & 0.88 \\
\hline AR Second & $4.20 \pm$ & $4.80 \pm$ & $4.00 \pm$ & $4.0 \pm$ & $3.50 \pm$ & $4.10 \pm$ & $4.30 \pm$ & $4.00 \pm$ \\
& 0.63 & 0.42 & 0.94 & 0.67 & 0.85 & 0.99 & 0.95 & 0.94 \\
\hline Stat. t & -0.88 & -0.49 & 0.26 & -1.33 & 0.58 & 0.22 & 0.27 & 0.25 \\
\hline Critical t & 2.10 & 2.10 & 2.10 & 2.10 & 2.10 & 2.10 & 2.10 & 2.10 \\
\hline $\begin{array}{c}\text { Statistical } \\
\text { difference }\end{array}$ & No & No & No & No & No & No & No & No \\
\hline
\end{tabular}

Table 2. Student $\mathrm{t}$ test for scores given to the post-game questionnaire after using the $\mathrm{AR}$ game, $\alpha=0.05$

\begin{tabular}{|c|c|c|c|c|c|c|c|c|}
\hline Questions & AG1 & AG2 & AG3 & AG4 & AG5 & AG6 & AG7 & AG8 \\
\hline Real First & $2.70 \pm$ & $3.4 \pm$ & $3.10 \pm$ & $2.60 \pm$ & $2.80 \pm$ & $4.20 \pm$ & $3.00 \pm$ & $4.20 \pm$ \\
& 0.82 & 0.84 & 1.20 & 1.27 & 1.14 & 1.14 & 1.16 & 0.79 \\
\hline Real Second & $2.10 \pm$ & $2.50 \pm$ & $2.40 \pm$ & $1.80 \pm$ & $1.90 \pm$ & $4.20 \pm$ & $3.20 \pm$ & $3.80 \pm$ \\
& 0.74 & 1.08 & 0.84 & 0.79 & 0.57 & 1.23 & 1.23 & 1.23 \\
\hline Stat. t & 1.72 & 2.08 & 1.51 & 1.70 & 2.24 & 0.00 & -0.38 & 0.87 \\
\hline Critical t & 2.10 & 2.10 & 2.10 & 2.10 & 2.10 & 2.10 & 2.10 & 2.10 \\
\hline $\begin{array}{c}\text { Statistical } \\
\text { difference }\end{array}$ & No & No & No & No & Yes & No & No & No \\
\hline
\end{tabular}

Table 3. Student $\mathrm{t}$ test for scores given to the post-game questionnaire after using the real game, $\alpha=0.05$

For the sense of presence, table 4 presents the data for the presence questionnaire. It shows Student $t$ test for the scores given after playing the two games. The analysis of the data indicates that there is no significant statistical difference between the two games. This implies that participants perceived the AR game as being real. In order to determine whether or not the order of play had effect on the scores in the second game, the sample was divided into two groups (the group of participants who played the real game first and the group of participants who played the AR game first). Student $t$ tests for the scores given to all questions were applied. No significant statistical differences were found (see Table 5). Therefore, the order of play did not influence the participants' scores for the presence questionnaire.

\begin{tabular}{|c|c|c|c|c|c|}
\hline Presence questionnaire & P1 & P2 & P3 & P4 & P5 \\
\hline AR & $5.90 \pm 0.91$ & $5.75 \pm 1.45$ & $5.70 \pm 1.66$ & $3.55 \pm 2.16$ & $6.05 \pm 1.43$ \\
\hline Real & $5.75 \pm 0.79$ & $5.80 \pm 2.04$ & $5.90 \pm 1.83$ & $4.25 \pm 1.97$ & $4.95 \pm 2.28$ \\
\hline Stat. t & 0.55 & -0.09 & -0.33 & -0.97 & 1.79 \\
\hline Critical t & 2.09 & 2.09 & 2.09 & 2.09 & 2.09 \\
\hline Statistical difference & No & No & No & No & No \\
\hline
\end{tabular}

Table 4. Student $\mathrm{t}$ test for scores given to the presence questionnaire after playing the two games, $\alpha=0.05$ 


\begin{tabular}{|c|c|c|c|c|c|}
\hline Presence questionnaire & P1 & P2 & P3 & P4 & P5 \\
\hline AR First & $6.00 \pm 1.05$ & $5.70 \pm 1.70$ & $5.20 \pm 1.87$ & $3.30 \pm 2.31$ & $6.50 \pm 1.08$ \\
\hline AR Second & $5.80 \pm 0.79$ & $5.80 \pm 1.23$ & $6.20 \pm 1.32$ & $3.80 \pm 2.10$ & $5.60 \pm 1.65$ \\
\hline Stat. t & 0.48 & -0.15 & -1.38 & -0.51 & 1.45 \\
\hline Critical t & 2.10 & 2.10 & 2.10 & 2.10 & 2.10 \\
\hline Statistical difference & No & No & No & No & No \\
\hline
\end{tabular}

Table 5. Student $\mathrm{t}$ test for scores given to the presence questionnaire playing the AR game, $\alpha=0.05$

With regard to the final questionnaire, we included the question: Which game did you like the most? (A2P1). All the participants (100\%) liked the AR game most. For the question: Did you feel comfortable wearing the HMD? (A2P2), the participants' score was 3.50 \pm 0.95 on a scale from 1 to 5 . For the question: What did you like the most? (A2P3), several answers included:

- Communicating with the computer using the cubes

- Watching the videos on the cubes

- Using the HMD

- The system ran very well

- The person in charge of the test was very professional

- The animals were very rare and I had not previously heard about hardly any of them

- The game was very different to the games I have seen until now.

For the question: What did you liked the least? (A2P4), several answers included:

- The HMD was big and heavy

- The theme of the game

- The system was not comfortable

- I got dizzy

- The style and size of the letters because they were not easy to read

- Some of the questions were difficult to understand.

\section{Conclusions}

We have presented an AR game that uses magnet and tangible cubes as the user interface to learn about different exotic animals. AR systems for learning have been cited in the related work section, but these systems have rarely been extensively evaluated. In this work, twenty participants took part in a study in which different aspects were evaluated (enjoyment and fun, perceived value, usability and sense of presence). First, for the fun aspect, the results indicate that participants perceived the AR game to be more fun than the real game. All the participants (100\%) liked the AR game most. Second, for the perceived value, the results indicate that participants preferred the AR game for its use for other purposes. They also thought that their friends would enjoy playing the AR game more than playing the real game. In addition, they would prefer to play with the AR game again. Third, we evaluated usability. The perceived level of easiness was similar for the two games. The participants liked to play using the cube for communication with the AR game more than they liked to play using the real game. Usability is considered as an important technical factor that affects educational effectiveness (Jones et al., 1999; Squires, 1999). For example, Kaufman 
(Kaufmann \& Schmalstieg, 2003; Kaufmann, 2004) evaluated usability using a question similar to ours: 'It is complex/easy to use'. Kaufman's results were $2.36 \pm 0.50$ on a scale from -3 to +3 . His result is not comparable to ours because the two systems are very different. However, we consider this question and the identification of usability to be important factors in AR systems. In our case, the score assigned to the real game was nearly the same as the AR game score, the participants did not report significant differences between the two games. This implies that the participants consider the AR game to be easy to use. Fourth, the sense of presence was evaluated. The presence questionnaires indicated that the AR game induced sense of presence in participants and that this sense of presence was similar to what they felt in a real environment. The main objective pursued in any VR or AR system is that the feeling of presence in a VR/AR environment be similar to the real world. These results are in accordance with those obtained by Usoh et al. (Usoh et al., 2000). These authors found nonsignificant differences in presence measures between real and virtual environments.

An aspect to highligth is that the interaction with the system is achieved using the tangible interface (cubes). The user does not touch the keyboard or the mouse to interact with the system. The partipants liked to play using the cube for communication with the AR game (AG7) more than they liked to play using the real game. Moreover, this interaction was one of the aspects of the AR game that participants like the most as several answers to this explicit question (A2P3) corroborate.

Although we have not evaluated our game as a pedagogical tool, we think it could be a good alternative for learning. Therefore, an exhaustive pedagogical evaluation could be performed. This would provide a more significant contribution to educational systems, particularly AR educational systems. The game can also be improved in several ways. First of all, we used monoscopic visualization. A stereoscopic visualization would be desirable. Second, the picture of animals could be substituted by 3D animals so that the participants could see the animals from different points of view. Third, with this game, it could be possible to teach/learn other subjects, such as plants/monuments of the world/etc. using different methods for classification. Changing these features is especially easy in our game because of its structure. The game could be used for other purposes and the results could be compared with the ones obtained in this work. Finally, several participants were of the opinion that the HMD was heavy and uncomfortable. It only weighs approximately 600 grams. Nevertheless, lighter HMD or other visualization systems could be considered.

To sum up, this system and other AR systems aimed for learning developed by the research group and other groups demonstrated that AR can complement successfully traditional teaching in a ludic way. However, more work has to be done in order to consolidate AR as a tool for learning.

\section{Acknowledgements}

Thanks to:

- Giacomo Toffetti for his assistance in developing and testing this system.

- The participants for collaborating in this study. 


\section{References}

Azuma, R. T. (1997). A Survey of Augmented Reality. Presence: Teleoperators and Virtual Environments, 6(4), 355- 385

Azuma, R.; Baillot, Y.; Behringer, R.; Feiner, S.; Julier, S. \& MacIntyre, B. (2001). Recent advances in augmented reality, IEEE Computer Graphics and Applications, 21, 34-37

Billinghurst, M.; Kato, H. \& Poupyrev, I. (2001). The Magic Book-Moving Seamlessly between Reality and Virtuality, IEEE Computer Graphics and Applications, 21 (3), 6-8

Bimber, O.; Fröhlich, B.; Schmalstieg, D. \& Encarnaçao, L.M. (2001). The virtual Showcase, IEEE Computer Graphics \& Applications, 21 (6), 48-55

Fjeld, M.; Fredriksson, J.; Ejdestig, M.; Duca, F.; Bötschi, K.; Voegtli, B.M. \& Juchli, P. (2007). Tangible User Interface for Chemistry Education: Comparative Evaluation and ReDesign, CHI 2007, 805-808

Jones, A.; Scanlon, E.; Tosunoglu, C.; Morris, E.; Ross, S.; Butcher, P.; et al. (1999). Contexts for evaluating educational software. Interacting with Computers, 11(5), 499-516

Juan. M.C.; Beatrice, F. \& Cano, J. (2008a). Augmented Reality for learning the interior of the Human Body, IEEE International Conference on Advanced Learning Technologies Learning technologies in the Information society (ICALT'08), 186-188

Juan. M.C.; Canu, R. \& Gimenez, M. (2008b). Augmented Reality Interactive Storytelling systems using tangible cubes for edutainment, IEEE International Conference on Advanced Learning Technologies Learning technologies in the Information society (ICALT'08), 233-235

Kato, H. \& Billinghurst, M. (1999). Marker tracking and HMD calibration for a video-based augmented reality, 2nd IEEE and ACM International Workshop on Augmented Reality (IWAR'99), 85-94, http://www.hitl.washington.edu/artoolkit

Kaufmann, H. \& Schmalstieg, D. (2003). Mathematics and geometry education with collaborative augmented reality, Computers \& Graphics, 27, 339-345

Kaufmann, H. (2004). Geometry Education with Augmented Reality, PhD Dissertation thesis, Vienna University of Technology

Larsen, L.B.; Jensen, R.B.; Jensen, K.L. \& Larsen, S. (2005). Development of an automatic pool trainer, Conference on Advances in Computer Entertainment Technology (ACE'05), 83-87

Mayo, M.J. (2007). Games for Science and Engineering Education. Communications of the ACM, 50(7), 31-35

McClean, P.; Saini-Eidukat, B.; Schwert, D.; Slator, B. \& White, A. (2001). Virtual worlds in large-enrollment science classes significantly improve authentic learning. The 12th International Conference on College Teaching and Learning, 111-118

Motokawa, Y. \& Saito, H. (2006). Support system for guitar playing using augmented reality display. Fifth IEEE and ACM International Symposium on Mixed and Augmented Reality (ISMAR'06), 243-244

Shelton, B.E.; Hedley, N.R. (2002) Using Augmented Reality for Teaching earth-sun relationships to undergraduate geography students, 1st IEEE International Augmented Reality Toolkit Workshop, 8 pag., http://depts.washington.edu/pettt/papers/shelton-hedley-art02.pdf

Slater, M.; Usoh, M. \& Steed, A. (1994). Depth of presence in virtual environments. Presence: Teleoperators and Virtual Environments, 3, 130-144 
Squire, K.; Barnett, M.; Grant, J. \& Higginbotham, T. (2004). Electromagnetism supercharged! Learning physics with digital simulation games. The 6th International Conference of the Learning Sciences, 513-520

Squires, D. (1999). Editorial. Usability and educational software design: Special issue of interacting with computers. Interacting with Computers, 11(5), 463-466.

Usoh, M.; Catena, E.; Arman, S. \& Slater, M. (2000). Using presence questionnaires in reality. Presence: Teleoperators and Virtual Environments, 9, 497-503

Virvou, M. \& Katsionis, G. (2008). On the usability and likeability of virtual reality games for education: The case of VR-ENGAGE. Computers \& Education, 50, 154-178

Woods, E.; Billinghurst, M.; Looser, J.; Aldridge, G.; Brown, D.; Garrie, B. \& Nelles, C. (2004). Augmenting the science centre and museum experience, GRAPHITE, 230-236 


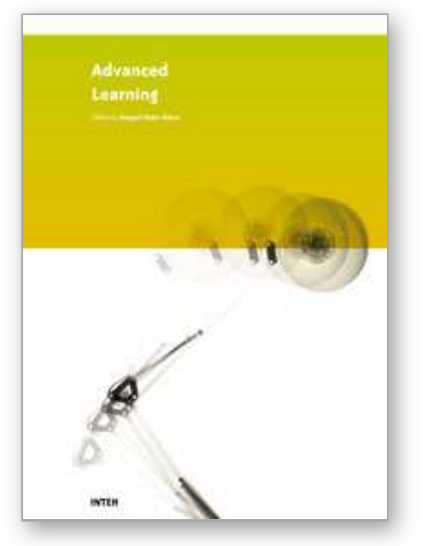

\section{Advanced Learning \\ Edited by Raquel Hijn-Neira}

ISBN 978-953-307-010-0

Hard cover, 444 pages

Publisher InTech

Published online 01, October, 2009

Published in print edition October, 2009

The education industry has obviously been influenced by the Internet revolution. Teaching and learning methods have changed significantly since the coming of the Web and it is very likely they will keep evolving many years to come thanks to it. A good example of this changing reality is the spectacular development of eLearning. In a more particular way, the Web 2.0 has offered to the teaching industry a set of tools and practices that are modifying the learning systems and knowledge transmission methods. Teachers and students can use these tools in a variety of ways aimed to the general purpose of promoting collaborative work. The editor would like to thank the authors, who have committed so much effort to the publication of this work. She is sure that this volume will certainly be of great help for students, teachers and researchers. This was, at least, the main aim of the authors.

\section{How to reference}

In order to correctly reference this scholarly work, feel free to copy and paste the following:

M. Carmen Juan Lizandra (2009). Augmented Reality and Tangible Interfaces for Learning, Advanced Learning, Raquel Hijn-Neira (Ed.), ISBN: 978-953-307-010-0, InTech, Available from:

http://www.intechopen.com/books/advanced-learning/augmented-reality-and-tangible-interfaces-for-learning

\section{INTECH}

open science | open minds

\section{InTech Europe}

University Campus STeP Ri

Slavka Krautzeka 83/A

51000 Rijeka, Croatia

Phone: +385 (51) 770447

Fax: +385 (51) 686166

www.intechopen.com

\section{InTech China}

Unit 405, Office Block, Hotel Equatorial Shanghai

No.65, Yan An Road (West), Shanghai, 200040, China 中国上海市延安西路65号上海国际贵都大饭店办公楼 405 单元

Phone: +86-21-62489820

Fax: +86-21-62489821 
(C) 2009 The Author(s). Licensee IntechOpen. This chapter is distributed under the terms of the Creative Commons Attribution-NonCommercial-ShareAlike-3.0 License, which permits use, distribution and reproduction for non-commercial purposes, provided the original is properly cited and derivative works building on this content are distributed under the same license. 